\title{
An Innovative Application of Nano-Technology in The Production of Hybrid Inorganic-Organic Coatings of Crude Oil Tanks
}

\author{
KAUTHER ELHABEEB BELGACEM ${ }^{1,2}$, HALA MOHAMED ABO-DIEF ${ }^{1,3 *}$ \\ and KHAMAEL MOHAMMED ABUALNAJA ${ }^{1}$
}
${ }^{1}$ Department of Chemistry, Faculty of Science, Al-Taif University, Kingdom of Saudi Arabia. ${ }^{2}$ University of Bizert. Tunisia laboratory Lacresne, Tunisia. ${ }^{3}$ Egyptian Petroleum Research Institute Nasr City, Cairo, Egypt.
${ }^{*}$ Corresponding author E-mail: Mohamed.hala91@yahoo.com

http://dx.doi.org/10.13005/ojc/340503

(Received: June 06, 2018; Accepted: September 15, 2018)

\begin{abstract}
Three corroded mediums that found in the crude oil have been applied to carbon steel specimens. The effect of the corrosion mediums concentration, application periods and times investigated. The Gravimetric method showed that sodium thiosulfate has the highest corrosion effect at all corrosion test parameters followed by sodium sulfate and sodium carbonate respectively. Each of Nano zinc oxide, Nano cotton cellulose and Nano banana cellulose protective films inhibit sodium thio sulfate corrosion effect. Anti-corrosion behaviour of the formed Nano films studied using gravimetric method (weight loss method), electrochemical method (potentiodynamic polarization) and scanning electron microscope (SEM) techniques. The nano zinc oxide heated at $700^{\circ} \mathrm{C}$ shown to have better inhibition efficiency followed by nano zinc oxide heated at $600^{\circ} \mathrm{C}$, Nano cotton cellulose and nano banana cellulose respectively. The potentiodynamic polarization measurements showed nano zinc oxide heated at $700^{\circ} \mathrm{C}$, Nano cotton cellulose, and nano banana cellulose the acted as mixed-type inhibitors with predominantly cathodic effectiveness. SEM techniques supported the achievement of corrosion inhibition with the presence of inhibitors.
\end{abstract}

Keywords: Nano polyvinyl alcohol, Nano cotton and banana cellulose, potentiodynamic polarization and Gravimetric methods, SEM images.

\section{INTRODUCTION}

Recently nanotechnology application gained momentum, and environmental impact. Due to their extremely fine grain size and high grain boundary volume fraction nano composites are known ${ }^{1-4}$. Nano technology used in agricultural systems, biomedicine, environmental engineering, safety and security, water resources, energy conversion, and numerous other areas ${ }^{5-9}$. Abo-Dief, Mostafa, Alzahrani, and Mohamed ${ }^{10}$ coated stainless steel oil pipes with chitosan $(\mathrm{CH})$,

This is an Open Access article licensed under a Creative Commons Attribution-Non Commercial-Share Alike 4.0 International License (https://creativecommons.org/licenses/by-nc-sa/4.0/), which permits unrestricted Non Commercial use, distribution and reproduction in any medium, provided the original work is properly cited. 
Nano iron oxide (NFE) and Nano activated carbon (NAC). Abo-Dief, Ebrahim, Altalhi, and Mohamed"11, Haniffa, Chin, Abdullah, Poh, and Chuah ${ }^{12}$, and Schincario $^{13}$ used epoxies (polymers) for the best concrete quality. Bianco, Tosco, and Sethi ${ }^{14}$ used two carbon based NPs and single layer graphene oxide (SLGO). Luo, Wang, Wei, Xiao, and $\mathrm{Ni}^{15}$ considered Nano-fluids have good properties of radiation absorption and heat transfer. Matteo, Candido, Vera, and Francesca ${ }^{16}$ concluded that Nanotech successfully used in drilling muds for the past 50 years. Walsh, Leon, Bavykin, Low, Wang, and Larson ${ }^{16}$ investigated nanostructured metallic coatings including Nano crystalline, and Nano composite types.

Protective painting systems include a primer and topcoat ${ }^{17}$. Saji ${ }^{18}$ deduced that for many years, coatings must have steel structures corrosion protection principal element. Drozdz, Hawkins, Clark, Surratt, Kingsley, Palutke, and Dean ${ }^{19}$ detected the polarization technique parameters effect on the oil pipelines corrosion. Galvanized steel with Nano composite has advantages in comparison with both the $\mathrm{ZnO}$ and PPy ${ }^{20-23}$. The oxidation/ corrosion of different metallic substrates improved using organic-inorganic hybrid coatings ${ }^{24-25}$. Al-Naamani, Dobretsov, Dutta, and Burgess ${ }^{26}$ used (chitosan- $\mathrm{ZnO}$ ) nanoparticle hybrid coatings and their antifouling activity tested. Abo-Dief, Morsi, and Mohamed ${ }^{27}$, and Abo-Dief, Al-Ghamdi, Al-Zahrani, and Mohamed ${ }^{28}$ showed that addition of Nano $\mathrm{Zn}$ in the deposition process increases the corrosion resistance. Abo-Dief ${ }^{29}$ used positron annihilation, in detecting $\mathrm{Zn}, \mathrm{ZnO}_{2}$ and $\mathrm{Zn}-\mathrm{ZSM}-5$ Nano powders properties. Abualnaja, and AboDief $^{30}$ synthesed silver nanoparticles by different types of plants and Vera, Schrebler, Cury, Del RI'o, Romero ${ }^{31}$ evaluated the corrosion protection of carbon steel using synthesed polyaniline and poly(ortho-methoxyaniline) (Poma). Abo-Dief, Emam, Abualnaja, and Mohamed ${ }^{32}$ producing the biodiesel from corn waste frying oil and five fresh vegetable oils (corn, rapeseed, sunflower, soybean and palm). Sherif, Saheb, El-Zatahry, kenawyand, and Alkaraki ${ }^{33}$ concluded that PVA and PVC coatings decrease the corrosion currents and corrosion rate of carbon steel. Pujari, S; Ramakrishna, A; and Kumar ${ }^{34}$ discussed the uses and applications of jute and banana fiber composites. The present work aimed at determining the Poly vinyl alcohol (PVA), Nano Banana and cotton cellulose and Nano zinc oxide coated carbon steel corrosion efficiency against one of three aggressive media; sodium thio sulfate, sodium sulfate and sodium carbonate. The effect of the corrosion test periods, temperature and corrosion media concentrations carried out and investigated.

\section{EXPERIMENTAL}

\section{Material Preparation}

Test specimens prepared by polishing, rinsing with distilled water, degreasing in ethanol, and drying at hot air. Carbon steel specimens corrosion test specimens performed with a rectangular form of $2.0 \mathrm{~cm} \times 1.0 \mathrm{~cm} \times 0.2 \mathrm{~cm}$ at an immersion time of; 24 h, $48 \mathrm{~h}, 72 \mathrm{~h}$ and $96 \mathrm{~h}$ at $25^{\circ} \mathrm{C}, 60^{\circ} \mathrm{C}$ and $100^{\circ} \mathrm{C}$. After immersion period, the specimens cleaned according and reweighed to $10-4 \mathrm{~g}$ for determining the weight loss. Three solutions; sodium thio sulfate, sodium sulfate and sodium carbonate of; $0.01 \mathrm{M}, 0.03 \mathrm{M}$ and $0.05 \mathrm{M}$ concentrations used at $100 \mathrm{ml}$ basic oil.

\section{Preparation of Coating Material}

Banana fruit and cotton fibers were purchased from local market and prepared as Nano cellulose. The concentration of both Nano materials mixed with water as; $1 \mathrm{~W}$ cellulose:10W water. Poly vinil Alcohol is purchased and used as a coating medium. Zinc oxide is also purchased from the local market and heat treated at $600^{\circ} \mathrm{C}$ and $700^{\circ} \mathrm{C}$ and cooled in furnace and used as a corrosion medium.

\section{Measurements \\ Gravimetric measurements}

After immersion period in the corrosion medium, the specimens cleaned and reweighed using a balance scale to $10-4 \mathrm{~g}$ for determining the weight loss. At each case, triplicate specimens used to get the mean value of the weight loss.

\section{Electrochemical measurements}

The specimens of the higher corrosion medium subjected to the electrochemical measurements. The overall current density values, $\mathrm{I}$, considered as the sum of two contributions, anodic and cathodic current la and Ic, respectively. The corrosion inhibition efficiency evaluated from the corrosion current densities values using the relationship (1): 
$\mathrm{IE}=\left[\left(\mathrm{Io}_{\text {corr }}-\mathrm{I}_{\text {corr }}\right) / \mathrm{Io}_{\text {corr }}\right] \times 100$

Where $\mathrm{I}_{\text {corr }}$ and $\mathrm{Io}_{\text {corr }}$ are the corrosion current densities values with and without inhibitor, respectively ${ }^{35}$. The surface coverage $(\theta)$ obtained from polarization curves for various concentrations of inhibitor using the following equation (2):

$\theta=1-\left(\mathrm{I}_{\text {corr }} / \mathrm{lo}\right.$ corr $)$

Where Icorr, and lo corr are the corrosion current densities values with and without inhibitor, respectively ${ }^{35}$.

\section{Electrochemical Studies}

Electrochemical studies carried using advanced corrosion measurement instrument. Three electrodes of carbon steel $1 \mathrm{cmX} 1 \mathrm{~cm} \times 0.5 \mathrm{~cm}$ as working electrode connected to anode, platinum as counter electrode connected to cathode and a reference electrode $\mathrm{Ag} / \mathrm{AgCl}$ used.

\section{Potentiodynamic Polarization Measurement (TAFEL)}

The TAFEL polarization curves obtained by scanning the electrode potential with respect to Ecorr with a scanning rate of $1 \mathrm{mVs}^{-1}$. The linear segments of the anodic and cathodic curves extrapolated to obtain the corrosion current densities $\mathrm{I}_{\text {corr }}$. Scanning Electron Microscope (Carl Zeiss Supra55 SEM) used to monitor the surface morphological changes.

\section{RESULTS AND DISCUSSIONS}

\section{Weight loss Results \\ Effect of corrosion medium concentration}

Figure 1 illustrated the effect of the three corrosion mediums concentrations of $0.01 \mathrm{M}(\mathrm{a})$, $0.03 \mathrm{M} \mathrm{(b)} \mathrm{and} 0.05 \mathrm{M}$ (c) on the carbon steel corrosion at different test periods and $25^{\circ} \mathrm{C}$. The results reveal that the amount of weight loss of carbon steel increases with the corrosion medium concentrations. This is due to the increment of the attacking action of the corrosion medium and the weakling effect of the carbon steel metal. The figure showed that sodium thio sulfate has the highest corrosion effect followed by sodium sulfate and sodium carbonate respectively. Also, the figure showed a corrosion effect of the basic oil due to the corrosion constituents that usually found in the crude oil. There is a weight loss increment related to the sodium carbonate corrosion medium due to the sticking of both the sodium carbonate particles with the loosed carbon steel particles on the carbon steel corroded specimen.

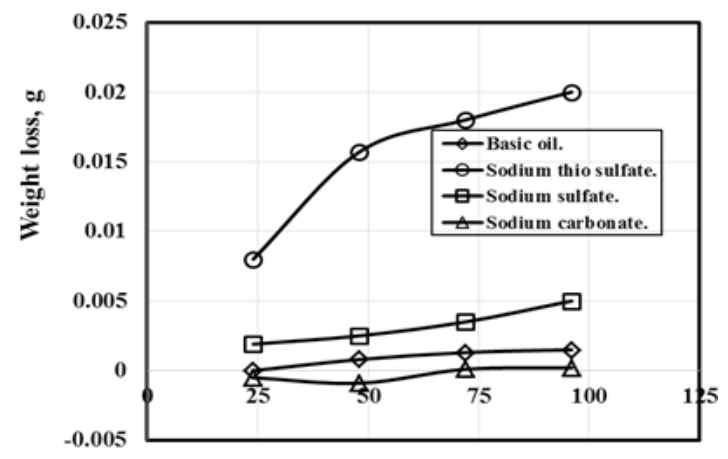

Test period, hrs

(a)

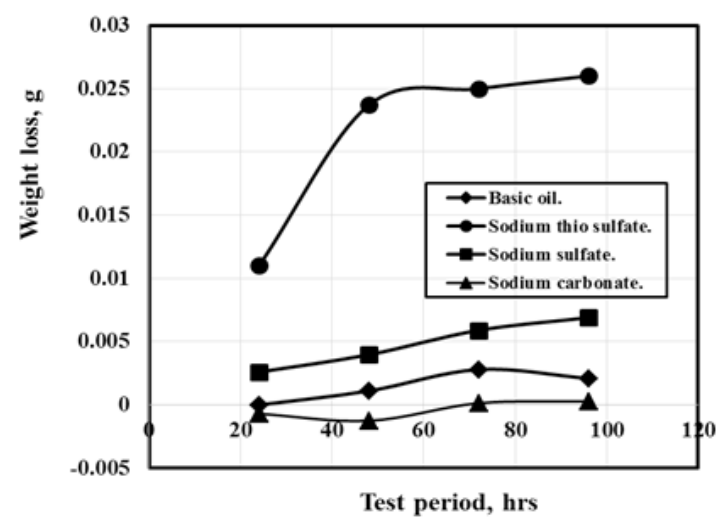

(b)

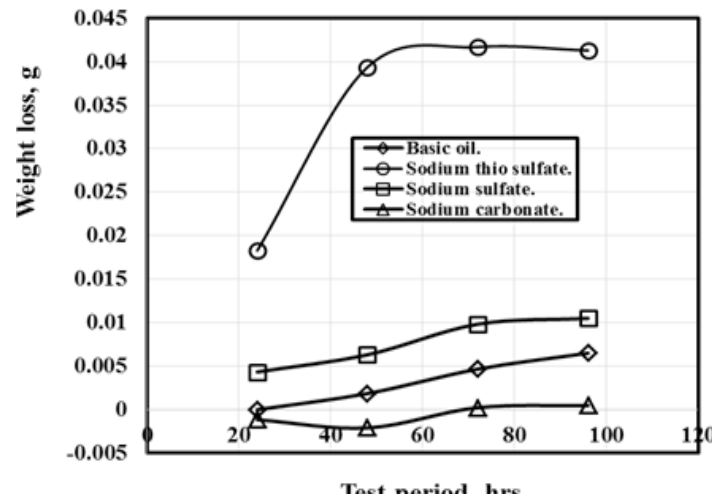

(c)

Fig. 1. Variation of corrosion medium concentration with the weight loss of the carbon steel specimens at various test periods at room temperature

\section{Effect of test period}

Figrue 2 illustrated the Variation of test period with the weight loss of the carbon steel 
specimens at various concentrations at $60^{\circ} \mathrm{C}$. it is clear that as the test period increases, the weight loss increases for all types of the corrosion mediums due to the increment application period of the carbon steel specimen to the attacking corrosion mediums that increases the weakness of the steel with time. As observed in 3.1.1. The sodium thio sulfate corrosion trend is found higher followed by sodium sulfate and sodium carbonate respectively.

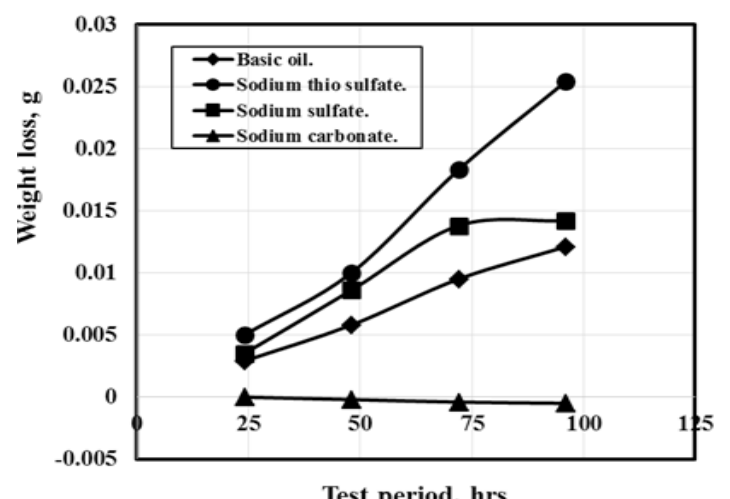

(a)

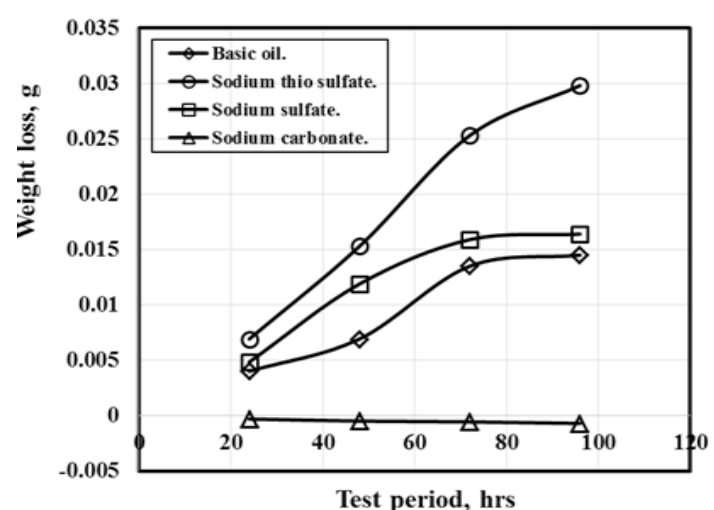

(b)

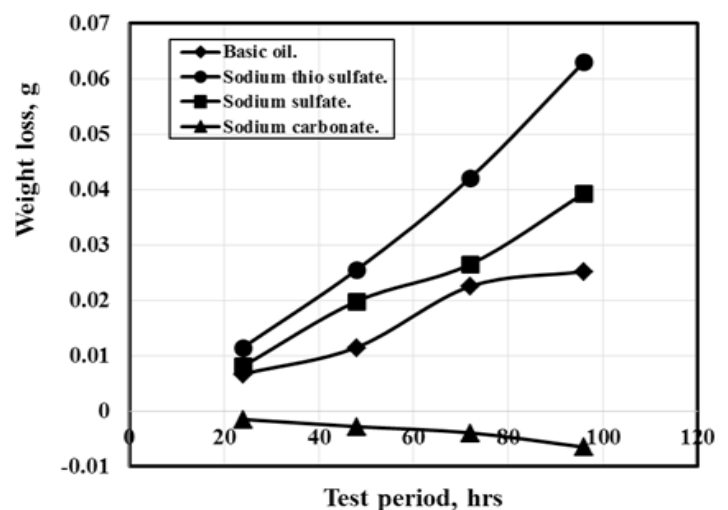

(c)

Fig. 2. Variation of test period with the weight loss of the carbon steel specimens at various concentrations at $60^{\circ} \mathrm{C}$

\section{Effect of test temperature}

Figure 3 showed that as the test temperature increases, the weight loss increases for all types of the corrosion mediums due to the weakening of the carbon steel specimen which facilitate the attacking corrosion mediums. As observed in 3.1.1. The sodium thio sulfate corrosion trend is found higher followed by sodium sulfate and sodium carbonate respectively.

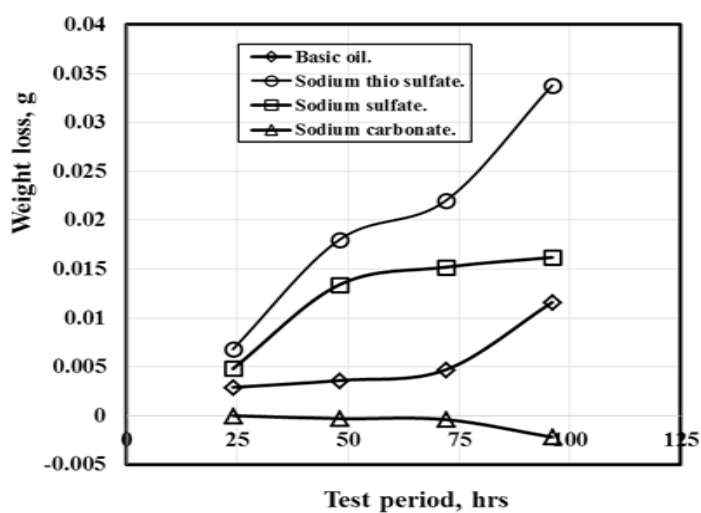

(a)

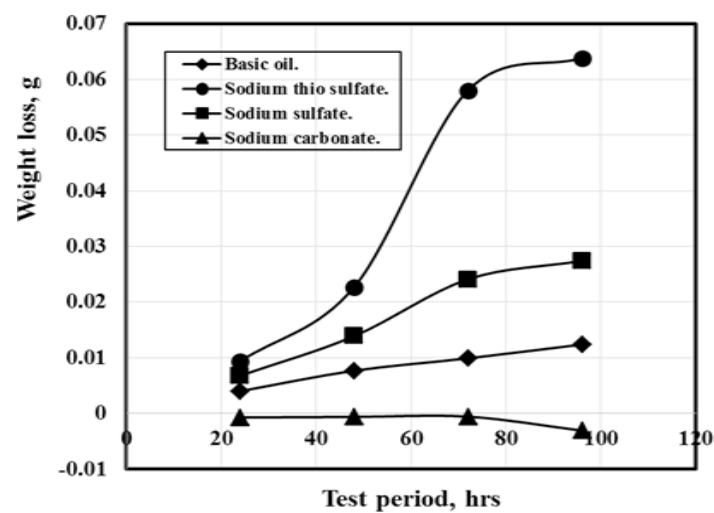

(b)

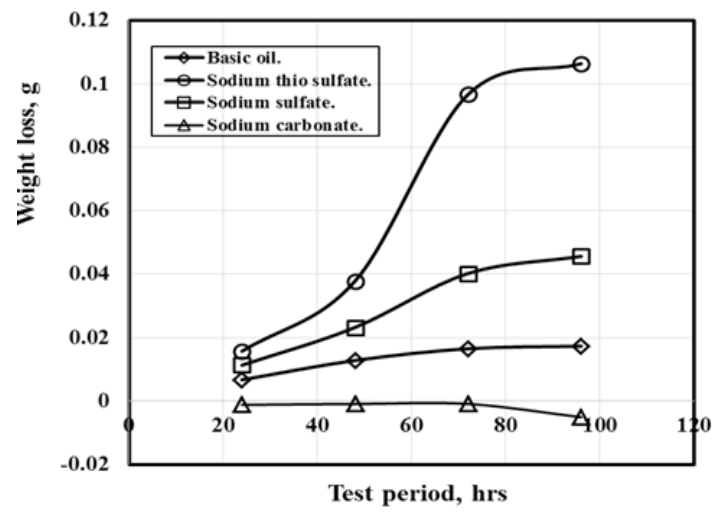

(c)

Fig. 3. Variation of test period with the weight loss of the carbon steel specimens at various concentrations at $100^{\circ} \mathrm{C}$ 


\section{Electrochemical Results}

Potentiodynamic polarization curves of carbon steel specimens immersed in the sodium thio sulfate the highest corrosion medium without and with Nano Polyvinyl-Alcohol (FE/PVL) zinc oxide at $600^{\circ} \mathrm{C}(\mathrm{FE} 600 \mathrm{ZnO})$, Nano banana cellulose (FE coat B), Nano cotton cellulose (FE coat C) and Nano zinc oxide at $700^{\circ} \mathrm{C}$ (Fe $700 \mathrm{ZnO}$ ) coating mediums are given Fig. 4. The current corrosion density $\left(I_{\text {corr }}\right)$, corrosion potential $(V)$, inhibition efficiency (E\%) and surface coverage values $(\theta)$ are given in Fig. 4 . Fig. 4a showed that carbon steel coated with Nano $\mathrm{ZnO}$ at $700^{\circ} \mathrm{C}$ has the lowest current corrosion density followed by carbon steel coated with Nano $\mathrm{ZnO}$ at $600^{\circ} \mathrm{C}$, Nano cotton cellulose, Nano banana cellulose, and Polyvinyl-Alcohol respectively with $\left(\mathrm{I}_{\text {corr }}\right)$ values of; $0.19,1.79,5.5,13.8$ and $17.2 \mathrm{~mA}$ respectively. So Nano $\mathrm{ZnO}$ at $700^{\circ} \mathrm{C}$ corrosion inhibitor has the highest corrosion resistance compared to the other corrosion inhibitors used. Also, it is clear that as the temperature increases, the inhibition effect of the coating increases in agreement with ${ }^{36-38}$ where the Icorr value decrement means the inhibitor concentration increment. The decrease in I ${ }_{\text {corr }}$ value indicates that decrease in flow of electrons, i.e., corrosion is supressed on the specimen.

Figure $4 \mathrm{~b}$ showed that carbon steel coated with Nano $\mathrm{ZnO}$ at $700^{\circ} \mathrm{C}$ has the lowest corrosion potential $\left(\mathrm{V}_{\text {corr }}\right)$ followed by Nano banana cellulose, Nano cotton cellulose, carbon steel coated with Polyvinyl-Alcohol, and $\mathrm{Nano} \mathrm{ZnO}$ at $600^{\circ} \mathrm{C}$ respectively with $\left(\mathrm{V}_{\text {corr }}\right)$ values of; 1.01, 1.07, 1.09, 717.0 and $911.0 \mathrm{mV}$ respectively. So, Nano $\mathrm{ZnO}$ at $700^{\circ} \mathrm{C}$ corrosion inhibitor has the lowest corrosion potential. As the Inhibitor classified as cathodic or anodic according to Vcorr value displacement from the control is greater than $85 \mathrm{mV}$. If the value is less than $85 \mathrm{mV}$ the inhibitor considered to be mixed type inhibitor. So the Nano $\mathrm{ZnO}$ at $700^{\circ} \mathrm{C}$ Nano banana cellulose and Nano cotton cellulose inhibitors considered as mixed inhibitor and effective towards cathodic inhibition inagrement with ${ }^{39}$.

Figure 4c showed that carbon steel coated with Nano $\mathrm{ZnO}$ at $700^{\circ} \mathrm{C}$ has the highest Inhibition efficiency $(E \%)$ by carbon steel coated with Nano $\mathrm{ZnO}$ at $600^{\circ} \mathrm{C}$, Nano cotton cellulose, Nano banana cellulose and Polyvinyl-Alcohol respectively with (E\%) values of; 99.5\%, 95\%, 84.9\%, 62.2\% and
$52.0 \%$ respectively. Comparing the inhibition efficiency of Nano $\mathrm{ZnO}$ at $700^{\circ} \mathrm{C}$ and Nano $\mathrm{ZnO}$ at $600^{\circ} \mathrm{C}$ indicated that the inhibition efficiency is temperature-dependent in agreement with ${ }^{37,39]}$.

Figure 4d showed that carbon steel coated with Nano $\mathrm{ZnO}$ at $700^{\circ} \mathrm{C}$ has the highest surface coverage $(\theta)$ followed by carbon steel coated with Nano $\mathrm{ZnO}$ at $600^{\circ} \mathrm{C}$, Nano cotton cellulose, Nano banana cellulose, and Polyvinyl-Alcohol respectively with $(\theta)$ values of; $0.995,0.9,0.849,0.622$ and 0.52 respectively. Comparing the Inhibition efficiency of Nano $\mathrm{ZnO}$ at $700^{\circ} \mathrm{C}$ and $\mathrm{Nano} \mathrm{ZnO}$ at $600^{\circ} \mathrm{C}$ indicated that the surface coverage is temperaturedependent in agreement with ${ }^{36,39}$. Since the surface coverage increases with temperature related to the change in the nature of the adsorption mode; the inhibitor is being physically adsorbed at lower temperatures, while Physisorption is favored by increasing of temperature. Thus, at high surface coverage, diffusion through the surface layer containing the inhibitor and corrosion products became the rate-determining step of the metal dissolution process ${ }^{37}$.

\section{Tafel polarization curves}

The potentiodynamic polarization measurement allowed for the study of anticorrosion behaviour via anodic and cathodic polarizations. The measurements recorded and analysed as TAFEL plots shown in Fig. 5 with the electrochemical parameters presented in Fig. 4. Fig. 5 illustrated the Tafel curves of Nano coatings. The corrosion potential is indicated by the intersection of the slopes of the cathodic and anodic branches of the curve. Fig. $5 a$ to $5 f$ showed the samples corrosion potential using various coating types. In agreement with the potentiodynamic test variables represented in Fig. 4, the test specimen containing coated with $\mathrm{ZnO}$ at $700^{\circ} \mathrm{C}$ has the lowest corrosion effect than the other coating mediums. $\mathrm{ZnO}$ inhibitor at $700^{\circ} \mathrm{C}$ banana and cotton has $\mathrm{E}_{\text {corr }}$ value displacement less than $85 \mathrm{mV}$. The result implies that the inhibitor used is mixed inhibitor and effective towards cathodic inhibition. Maximum efficiency found to be $99.95 \%$ with $\mathrm{ZnO}$ coating at $700^{\circ} \mathrm{C}$.

\section{Surface Examination}

Carbon steel surface before subjected to 0.05M sodium thio sulfate shown in Fig 6.a. Carbon steel coated with Nano PVL, Nano cotton cellulose, 
Nano banana cellulose, Nano $\mathrm{ZnO}$ at $600^{\circ} \mathrm{C}$ and Nano $\mathrm{ZnO}$ at $700^{\circ} \mathrm{C}$ subjected to $0.05 \mathrm{M}$ sodium thio sulfate shown in Fig. $6 \mathrm{~b}$ to $6 \mathrm{e}$. The SEM results showed that in the absence of inhibitor, more oxidized product in the metal surface with more

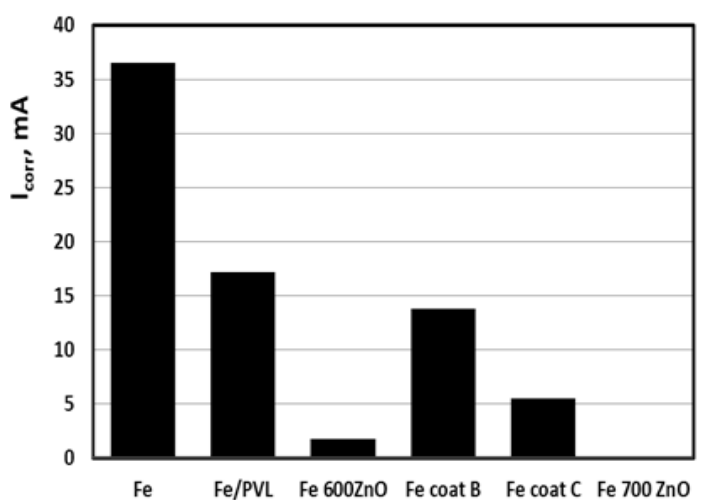

(a)

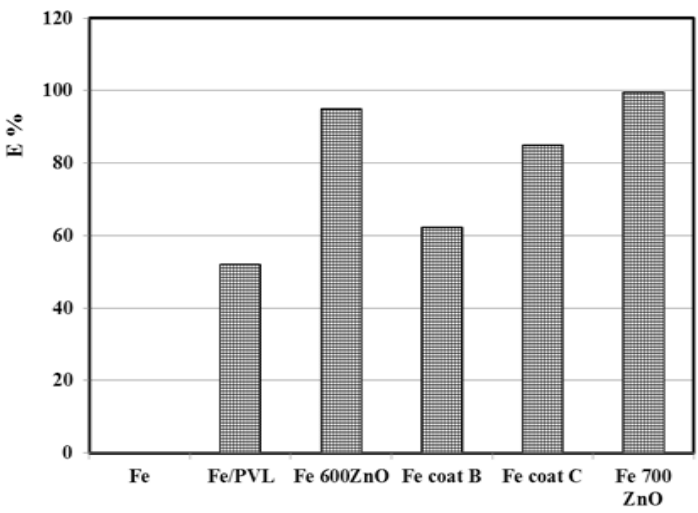

(c) damages. Where in the presence of inhibitor, there is little corrosion takes place in the surface due to its binding to the metal which visible in the SEM images. $\mathrm{ZnO}$ coating at $700^{\circ} \mathrm{C}$ showed the best surface coverage.

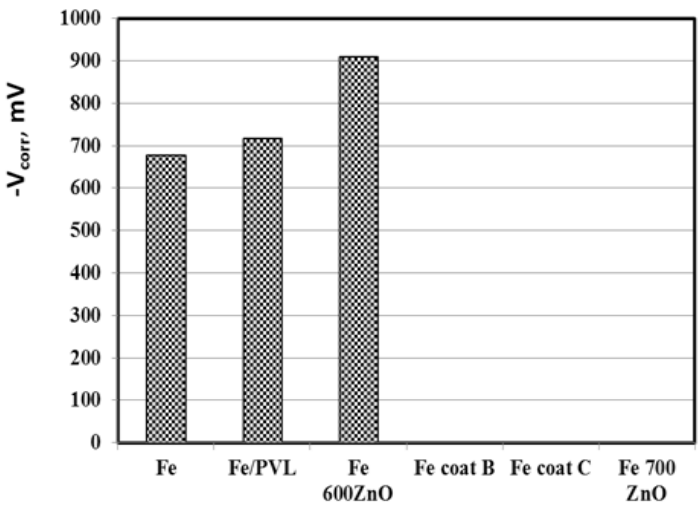

(b)

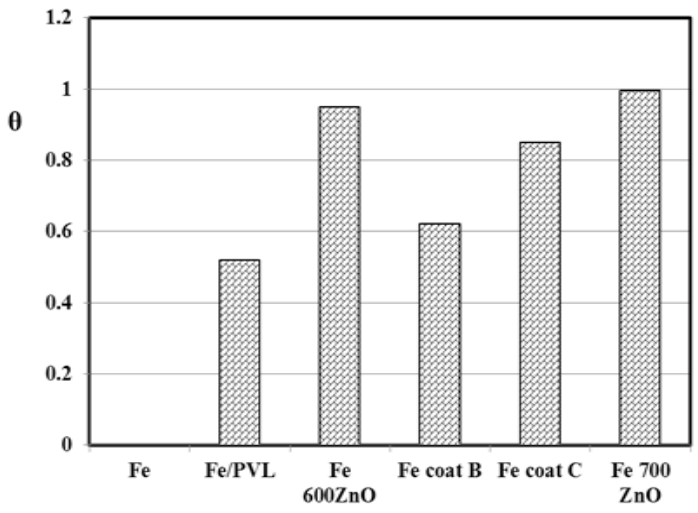

(d)

Fig. 4. Potentiodynamic polarization test values for all types of coating mediums
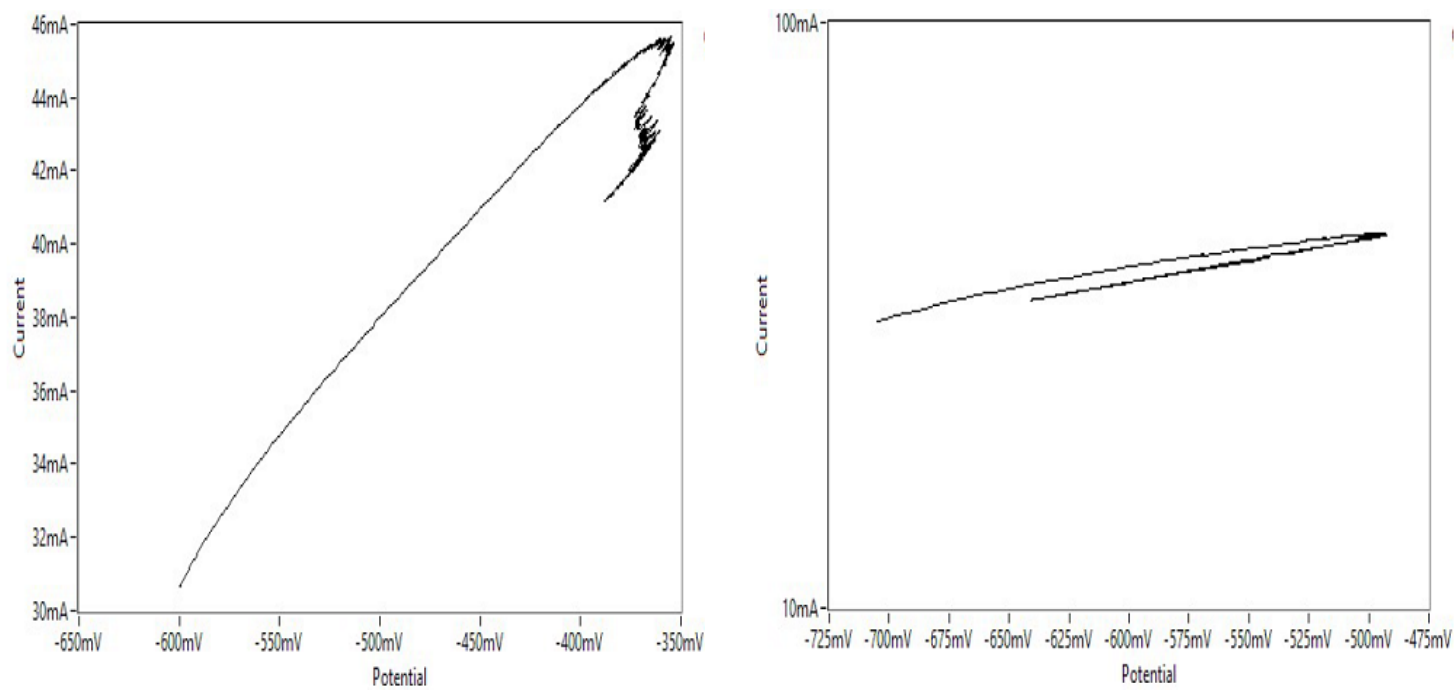

(a) 

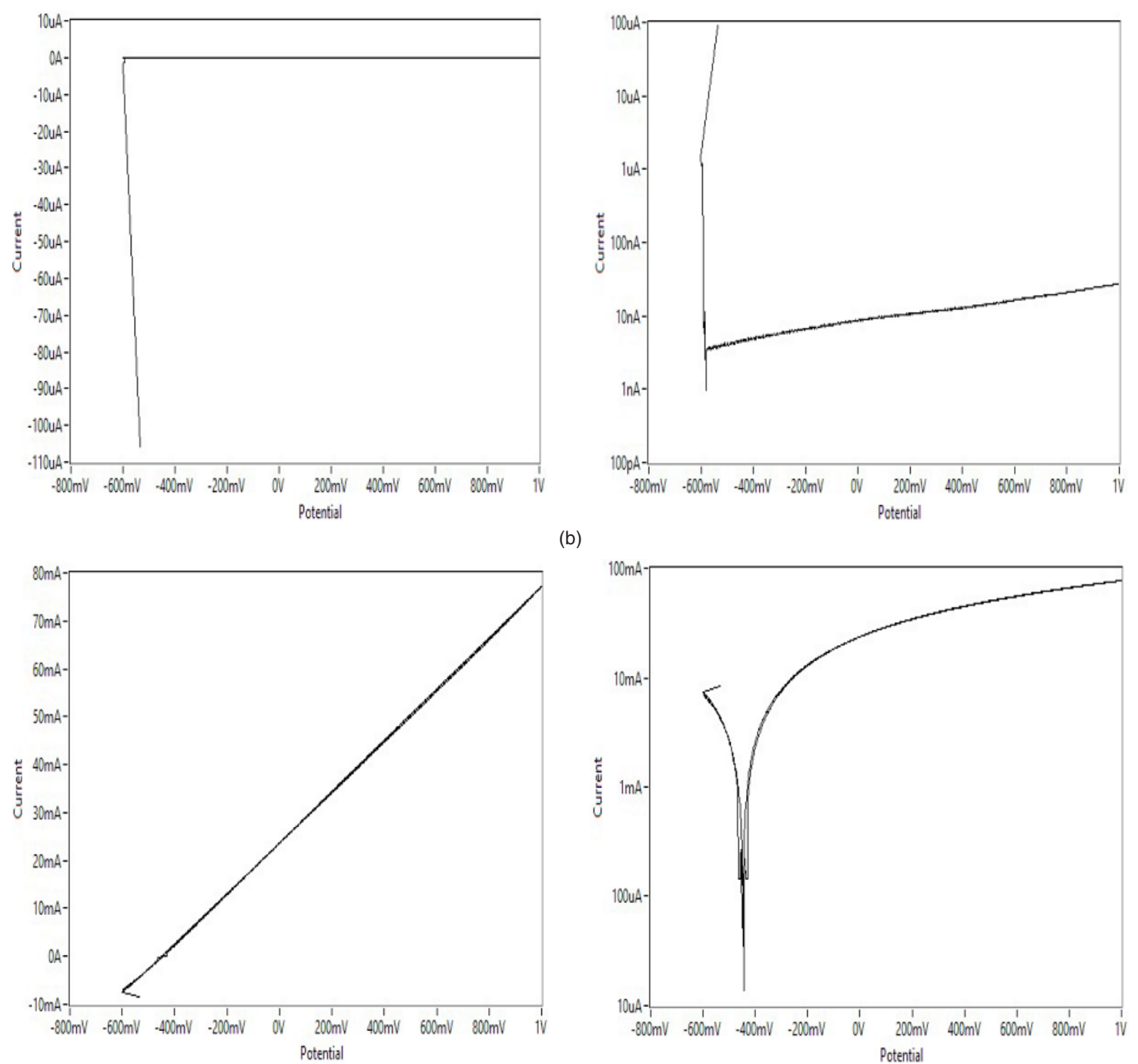

(c)
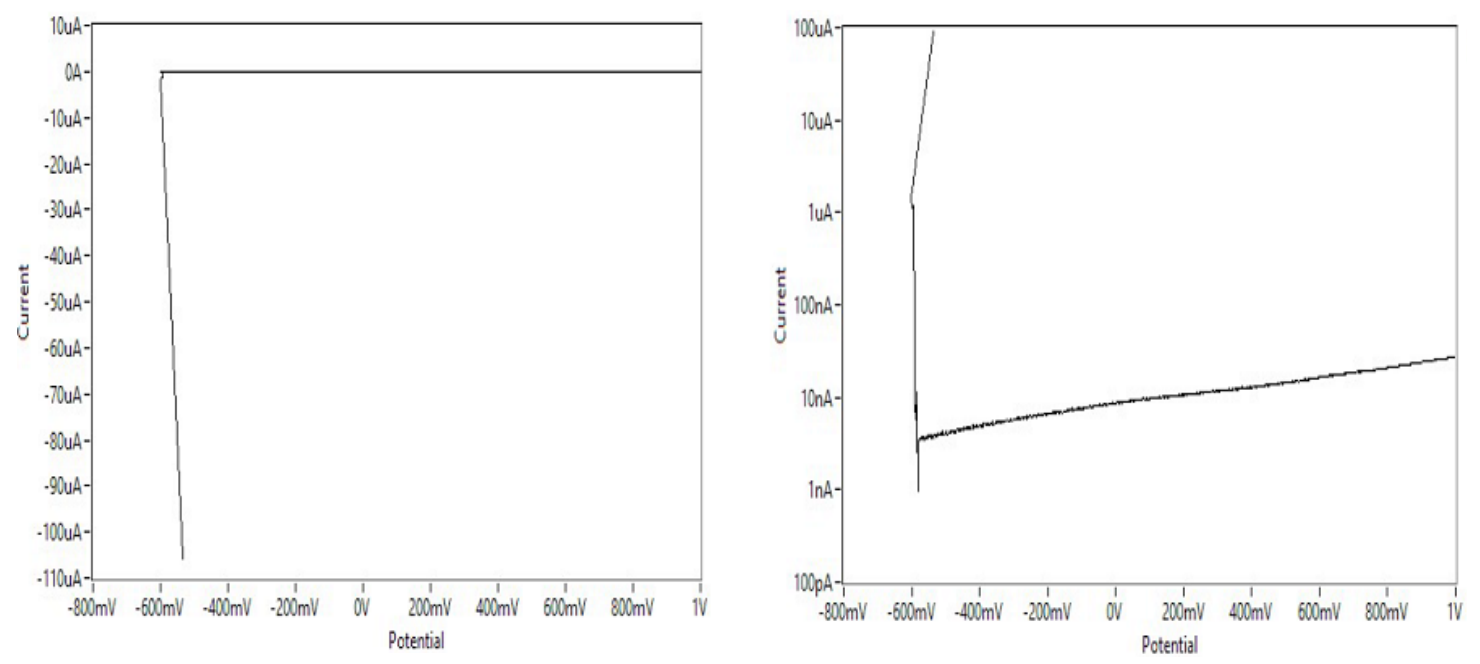

(d) 

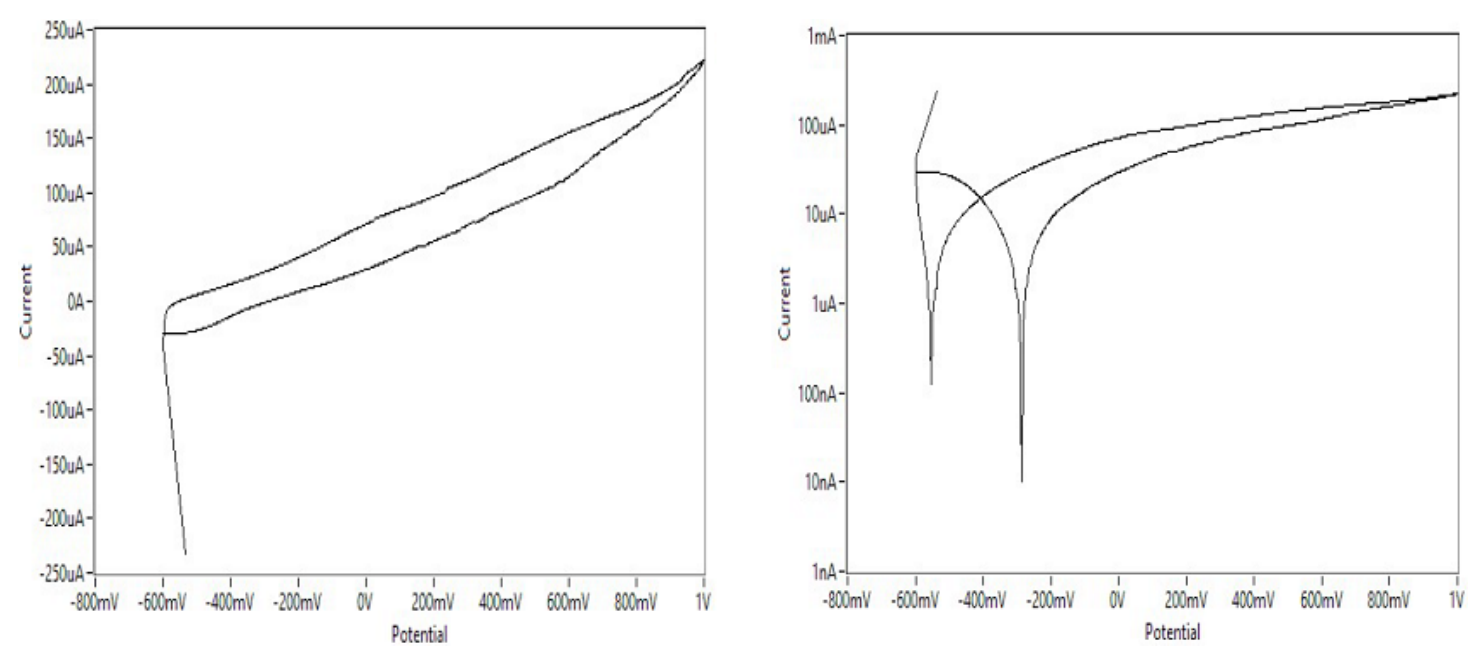

(e)
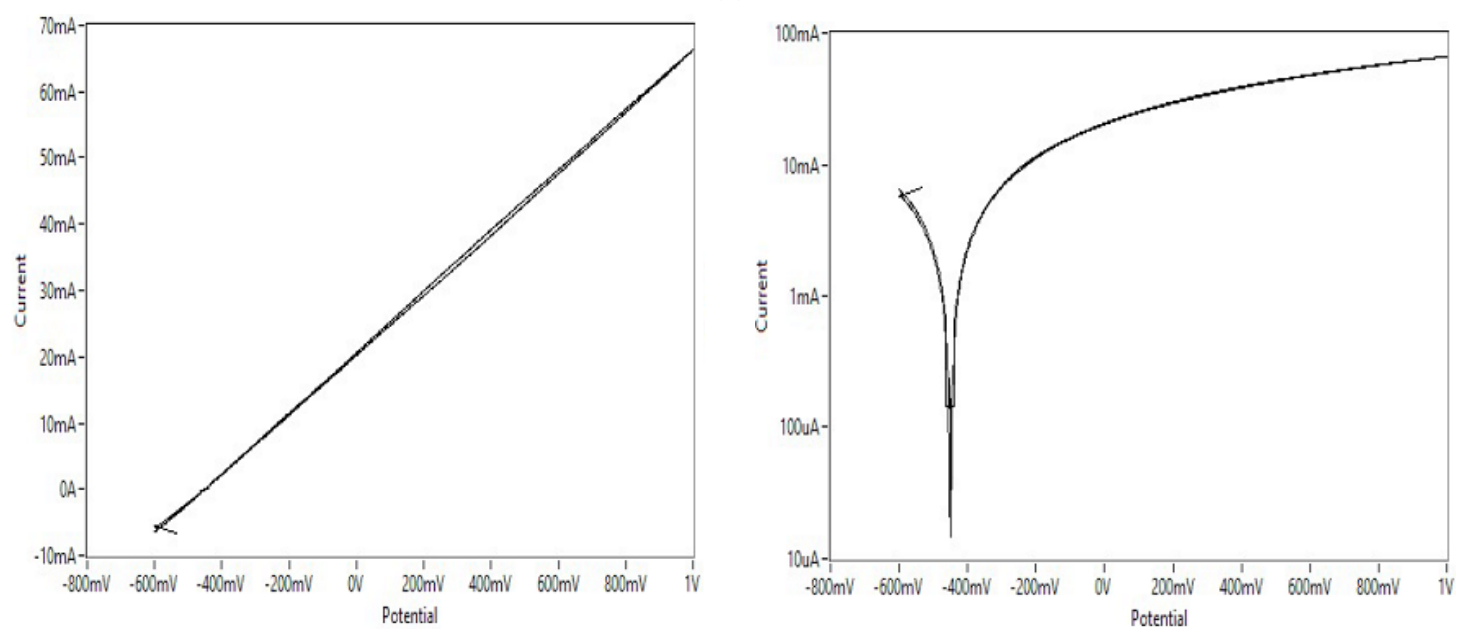

(f)

Fig. 5. Cyclic voltametry Tafel plots of carbon steel corroded at $0.05 \mathrm{M}$ sodium thio sulfate with (a) no coating at $100^{\circ} \mathrm{C}$, (b) coated with PVA, (c) coated with cotton, (d) coated with $\mathrm{ZnO}$ at $600^{\circ} \mathrm{C}$, (e) $\mathrm{ZnO} 700^{\circ} \mathrm{C}$ and (f) coated with banana

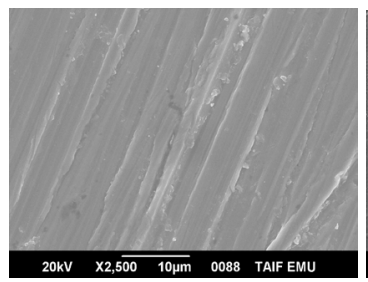

(a)

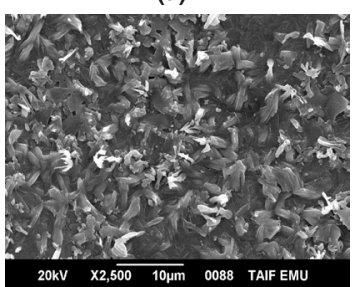

(d)

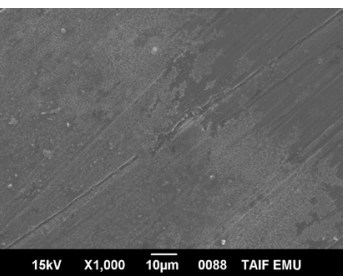

(b)

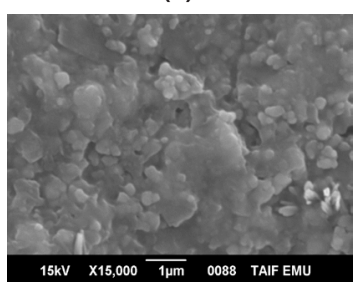

(e)

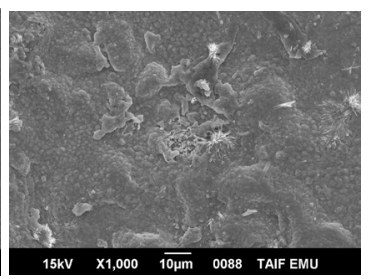

(c)

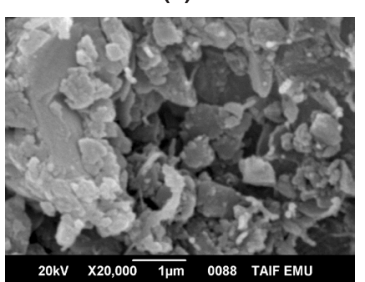

(f)

Fig. 6. SEM images of carbon steel subjected to $0.05 \mathrm{M}$ sodium thio sulfate (a) before coating, (b) after PVA coating, (c) coated with cotton, (d) coated with $\mathrm{ZnO}$ at $600^{\circ} \mathrm{C}$, (e) $\mathrm{ZnO} 700^{\circ} \mathrm{C}$ and (f) coated with banana 


\section{CONCLUSION}

\section{The following observations obtained}

a) As the corrosion medium concentration, test temperature and test periods increases, the corrosion effect increases.

b) Sodium thio sulfate has the highest corrosion effect followed by sodium sulfate and sodium carbonate respectively.

c) The Nano zinc oxide heated at $700^{\circ} \mathrm{C}$ shown to have better inhibition efficiency followed by Nano zinc oxide heated at $600^{\circ} \mathrm{C}$, Nano cotton cellulose, Nano banana cellulose and Nano polyvinyl alcohol respectively.

d) Potentiodynamic polarization parameters $\left(I_{\text {corr }}, V_{\text {corr }}, \theta\right.$. and $\left.\mathrm{E} \%\right)$ show that the used inhibitors adsorbed on carbon steel surface.

e) Good agreement observed between electrochemical curves and scanning electron microscopy images.

f) Polarization study reveals that Nano-zinc oxide heated at $700^{\circ} \mathrm{C}$, Nano cellulose cotton, and Nano cellulose banana systems formulation are mixed type of inhibitor.

\section{ACKNOWLEDGEMENT}

Authors are thankful to Al-Taif University for sponsoring and supporting this research under the project No (1-438-5622) and enabling us to develop this work.

\section{REFERENCES}

1. Abo-Dief, $\mathrm{H}_{\text {; }}$ Belgacem $\mathrm{K}$, and Mohamed, $\mathrm{A}$; RJPBCS., 2017, 8(4), 52-60.

2. Javed, Mohammed; IJSRD., 2015, 2(11), 8-12.

3. Pandey, R; Krishna, S; Rana, J; and Hazarika, N; IJTRE., 2016, 3(10), 3087-3090.

4. Wansah, J; Udounwa, A; Ahmed, A; Essiett, A; and Jackson, E; Proceedings of the 1st African Int.Conf./ Workshop on Applications of Nanotechnology to Energy, Health and Environment, UNN, pp. 103-110, March 2014, 23-29.

5. Orabi, R; Abo-Dief, H; Altalhi, A; and Mohamed, A; RJPBCS., 2016, 7, 815- 824.

6. Manjunatha, S; Biradar, D; And Aladakatti, Y; J. Farm Sci., 2016, 29(1), 1-13.

7. Adeleye, A; Conway, J; Garner, K; Huang, Y; Su, ; and Keller, Y; Chemical Engineering Journal, 2016, 286.

8. Ahmed, Z; Bilal, K; Khan, A; and Riaz, N; IJCEM., 2015, 1(12), 11-58.

9. Kunduru, K; Nazarkovsky, M; Farah, S; Pawar, R; Basu, A; Domb, A; Elsevier Inc., 2017, 33-74.

10. Abo-Dief, H;Mostafa, N;Alzahrani, E; and Mohamed, A; (RJPBCS)., 2016, 7(4), 2999-3007.

11. Abo-Dief, H; Ebrahim, F; Altalhi, A; and Mohamed, A; IJAST., 2015, 5, 43-52.

12. Haniffa, M; Chin; Abdullah, L; Poh, S; and Chuah, C; Polymers., 2016, 8(7), 246, 1-12.

13. Schincario, S.; Ph.D., Universita' Degli Studi Di Padova Dipartimento, 2016.

14. Bianco, C, Tosco, T; and Sethi, R; Contaminant Hydrology J., 2016, 93, 10-20.

15. Luo, Z; Wang, C; Wei, W; Xiao, G; and Ni,
M; International Journal of Heat and Mass Transfer., 2014, 75, 262-271.

16. Matteo, C; Candido, P; Vera, R; and Francesca, V; AJAS., 2012, 9(6), 784-793.

17. Peng, H; Text Book., 2010, 333-387.

18. Saji, V; Recent Patents on Corrosion Science., 2010, 2, 6-12.

19. Drozdz, S; Hawkins, T; Clark, L; Surratt, M; Kingsley, J; Palutke, K; and Dean, J; US Army Crops., 2011, 1-127.

20. Amanzadeha, $\mathrm{H}$; Yaminia, $\mathrm{Y}$; and Moradi, $\mathrm{M}$; Analytica Chimica Acta., 2015, 884, 52-60.

21. Walzade, S; and Tarannum, N; IRJET., 2016 3(8),1277-1281.

22. Cocuzza, M; Pirri, F; Rocca, V; and Verga, F; Politecnico di Torino, The Offshore Mediterranean Conference and Exhibition in Ravenna, Italy, 2011, 1-17.

23. Umoren, S; and Solomon, M; The Open Materials Science J., 2014, 8, 39-54.

24. Xie, G; Luo, P; Deng, M; and Wang, Z; J. of Nanomaterials Volume., 2015, 1-8.

25. Figueira, R; Silva, C; and Pereira, E; J. Coat. Technol. Res., 2015, 12(1), 1-35.

26. Al-Naamani, L; Dobretsov, S; Dutta, J; and Burgess, J; Chemosphere., 168, 2017, 408-417.

27. Abo-Dief, H; Morsi, S; and Mohamed, A; IJASTR., 2013, 3(6), 787-797.

28. Abo-Dief, H; Al-Ghamdi, S; Al-Zahrani, E; and Mohamed, A; The AES-ATEMA'2014 Seventeen Int. Conf. Montreal, CANADA, 2014, 201-211. 
30. Abualnaja, K; and Abo-Dief, H; The IJCM Engineering., 2017, 4, 6.

31. Vera, R; Schrebler, R; Cury, P; Del Rı'o, ; Romero, R; J Appl Electrochem., 2007, 37, 519-525

32. Abo-Dief, H; Emam, A; Abualnaja, K; And Mohamed, A; Under Publication, Orient. J. Chem., 2018, 34(2).

33. Sherif, E; Es-saheb, M; El-Zatahry, A; kenawyand, E; and Alkaraki; Int. J. Electrochem. Sci., 2012, 7, 6154 - 6167.

34 Pujari, S; Ramakrishna, A; and Kumar, M; IJCT., 2014., 2, 120-126.
35. Alaoui, K; El Kacimi, Y; Galai, M; Touir, ; Dahmani, R; Harfi, A; and Ebn Touhami, M; J. Mater. Environ. Sci., 2016, 7(7), 2389-2403.

36. Gehlot, P, Daga, K; and Mehta, R; Int. J. of Chemistry., 2011, 3(3), 56-61.

37. Senthilvadivu, B; Aswini, V; and Kumar, K; IJSR., 2017, 6(7), 1762-1768.

38. Sangeetha, M; Rajendran, S; Sathiyabama, J; and Prabhaka, P; J. Nat. Prod. Plant Resour., 2012, 2(5), 601-610.

39. Palanisamy, K; Devabharathi, V; and Sundaram, N; IJCTR., 2015, 7, 1661-1664. 